\title{
Perfil epidemiológico e social de crianças e adolescentes com Anemia Falciforme e sua relação com a cárie dentária
}

\author{
Epidemiological and social profile of children and adolescents with sickle cell anemia \\ and association with dental caries
}

\author{
Amanda Vervloet Dutra Agostinho Assis ${ }^{1}$, Ana Carla Robatto Nunes², Iza Teixeira Alves Peixoto ${ }^{3}$, Viviane \\ Maia Barreto de Oliveira ${ }^{4}$, Ana Marice Teixeira Ladeia ${ }^{5}$, Carla Figueiredo Brandão ${ }^{6^{*}}$

\begin{abstract}
${ }^{1}$ Mestre em Clínica Odontológica - UFRJ; ${ }^{2}$ Doutora em Microbiologia - USP.; ${ }^{3}$ Doutora em Microbiologia e Imunologia em Odontologia - UNICAMP; ${ }^{2}$ Doutora em Clínica Odontológica - UNICAMP; ${ }^{5}$ Doutora em Medicina e Saúde - UFBA; ${ }^{6}$ Doutora em Medicina e Saúde Humana - EBMSP.
\end{abstract}

\begin{abstract}
Resumo
Introdução: a Anemia Falciforme (AF) é a patologia hereditária monogênica mais prevalente associada à presença de hemoglobina SS no mundo. Pode provocar alterações no corpo, face e dentes dos indivíduos afetados, que podem levar a uma maior predisposição ao desenvolvimento da cárie dentária. Objetivo: avaliar o perfil epidemiológico e social de crianças e adolescentes com AF, a prevalência de cárie e influência da dieta. Metodologia: estudo de corte transversal com 124 indivíduos de 5 a 18 anos provenientes do ambulatório de referência em AF para o grupo AF ( $n=61$ ) e sem hemoglobinopatias matriculados em colégio público da Bahia ( $n=63$ ) para o grupo comparação. Anamnese, exame dos dentes e aplicação de questionários sobre a condição de saúde, história da doença e dieta foram realizados. Resultados: a maioria era da raça parda, cursava o 10 grau, a renda era de um salário mínimo, mas em relação à procedência, a maioria das crianças com AF era do interior. Estas também frequentavam mais as consultas odontológicas, apesar de o CPO-D ter sido maior (CPO-D=2,1) que o grupo comparação (CPO-D=1,1), bem como o ceo-d de 2,3 e 0,88, respectivamente. Crianças e adolescentes com AF consumiam menos carboidratos e tiveram um índice de cárie mais alto (ceo- $d=2,0 ; C P O-D=4,2)$ que os do grupo comparação (ceo- $d=0,9 ; C P O-D=1,0$ ). $O$ grupo com $A F$ apresentou nível socioeconômico baixo e maior índice de cárie em ambas as dentições, apesar da dieta ter sido menos cariogênica. Conclusão: é possível que a prevalência maior de cárie para indivíduos com AF esteja associada a outros fatores inerentes à doença.
\end{abstract}

Palavras-chave: Anemia falciforme. Criança. Saúde bucal. Cárie dentária.

\begin{abstract}
Introdution: sickle cell anemia (SCA) is the most prevalent hereditary monogenic pathology associated with the presence of SS hemoglobin in the world. It can affect ibody, face and teeth, which can lead to a higher predisposition to the development of dental caries. Objective: evaluate the epidemiological and social profile of children and adolescents with Sickle Cell Anemia (SCA), prevalence of caries and influence of diet. Methodology: a cross-sectional study was realized with 124 individuals ages of 5 to 18 years originated from the reference ambulatory in SCA for the SCA group ( $n=61)$ and without SCA matriculate in a public school in Bahia ( $n=63)$ for the comparation group. Anamnesis, teeth examination and application of questionnaires about health condition, disease and diet history were realized. Results: most of them were brown, was in elementary school, income of a minimum wage, but in relation to provenance, most children with SCA were from the countryside. These ones also attended more dental consultations, although the DMFT was higher than the comparation group, 2.1 and 1.1, as well as the dmft 2.3. and 0.88, respectively. Children and adolescents with SCA consumed less carbohydrates and had a higher caries index ( $d m f t=2.0 ; D M F T=4.2)$ than those in the comparation group $(d m f t=0.9 ; D M F T=1.0)$. The group with SCA presented low socioeconomic level and higher caries index in both dentitions, even if the diet was less cariogenic. Conclusion: it is possible that higher prevalence of caries for individuals with SCA may be associated with other factors inherent to the disease.
\end{abstract}

Keywords: Sickle cell anemia. Child. Oral Health. Dental caries.

\section{INTRODUÇÃO}

Doença Falciforme (DF) é um termo genérico que se refere às alterações genéticas caracterizadas pela alteração da molécula de hemoglobina $(\mathrm{Hb})$. As DFs mais frequentes são a Anemia Falciforme (AF) que é a expressão

Correspondente/Corresponding: *Carla Figueiredo Brandão-End.: Av. Silveira Martins, 3386, Cabula, CEP: 41150-000, Salvador - BA (Escola Bahiana de Medicina e Saúde Pública - Tel: (71) 3257-8200 - E-mail: cfbrandao@hotmail.com clínica do gene da Hb S em homozigose (HbSS), a S beta talassemia e HbSC e HbSD. No Brasil, nascem cerca de 3.000 crianças com DF anualmente e 200.000 com traço falcêmico ${ }^{1}$. A incidência para a doença é de 1:1.000 e de 1:35 para o traço falcêmico, sendo que no estado da Bahia, onde ocorre a maior proporção de casos registrados, esta incidência é de 1:650 e 1:17, respectivamente ${ }^{2}$. A frequência de recém-nascidos com hemoglobinopatias em 581 neonatos provenientes de uma maternidade de referência em Salvador foi de 101 casos $(17,4 \%)$ com hemoglobinas variantes, sendo que o traço falciforme esteve presente em $9,8 \%$ e a AF em $0,2 \%$ dos recém-nascidos ${ }^{3}$. 
A AF consiste na doença hereditária mais frequente no Brasil, atingindo principalmente afrodescendentes ${ }^{4}$. $E$ causada por mutação na posição 6 da cadeia da $\beta$-globina, no cromossomo 11, pela substituição de uma adenina (A) por uma timina (T) (GAG => GTG), codificando o aminoácido valina em vez de ácido glutâmico e, originando, assim, a hemoglobina variante $\mathrm{Hb} \mathrm{S}$. Essa modificação produz alteração estrutural na molécula da $\mathrm{Hb}$, que assume forma de foice em decorrência do processo de polimerização fisiologicamente provocado pela baixa tensão de oxigênio, causando vaso-oclusão, impedindo o fluxo sanguíneo e promovendo anóxia tecidual, infarto, necrose e dor ${ }^{5,6}$.

As manifestações orais não são patognomônicas, mas podem ser observadas alterações como: palidez das mucosas, anomalias radiográficas, distúrbios de mineralização do esmalte e dentina, má oclusão, hipercementose, doença periodontal, parestesia do nervo alveolar, necrose pulpar assintomática e cárie ${ }^{7,8}$.

Indivíduos com AF podem apresentar características locais e sistêmicas que, associadas a condições socioeconômicas, predisponham ao desenvolvimento de doenças bucais, como a cárie, devido à alta prevalência de opacidades nos dentes decorrentes de alterações na formação e calcificação do esmalte e da dentina, além do uso frequente de medicações contendo sacarose e alta frequência de hospitalizações, dificultando a higiene bucal adequada? .

Dessa forma, o objetivo do presente estudo foi avaliar o perfil epidemiológico e social de crianças e adolescentes com diagnóstico de AF, bem como a prevalência de cárie e a influência da dieta nestes indivíduos.

\section{METODOLOGIA}

Estudo de corte transversal realizado com crianças e adolescentes de 5 a 18 anos com AF acompanhados pela Fundação de Hematologia e Hemoterapia da Bahia (HEMOBA) e sem hemoglobinopatias e saudáveis matriculadas no Colégio Estadual Francisco da Conceição Menezes, pareados por sexo e faixa etária.

Foram incluídos no estudo crianças e adolescentes com diagnóstico de AF confirmado por eletroforese de $\mathrm{Hb}$ e/ou cromatografia líquida de alta performance para o grupo AF. Por outro lado, indivíduos usuários de aparelho ortodôntico, portadores de Doença Falciforme ( $\mathrm{Hb}$ AS, $\mathrm{Hb}$ $\mathrm{SC}, \mathrm{Hb} \mathrm{SB}, \mathrm{Hb} \mathrm{SB}+, \mathrm{Hb} S B-)$, indivíduos com comorbidades (diabetes mellitus, neoplasias malignas) e aqueles que se recusaram a assinar o termo de assentimento/consentimento foram excluídos da pesquisa.

A coleta de dados seguiu os padrões daquela realizada pela Equipe de Campo do Projeto SB Brasil 2010 e, para calibração do único avaliador, realizou-se treinamento teórico e prático para o reconhecimento da condição de saúde bucal avaliada e padronização dos exames bucais e critérios de diagnóstico. Em razão disso, doze crianças e adolescentes foram examinados em dois momentos, separados por um intervalo de três meses entre as sessões, e foi realizado o cálculo do coeficiente Kappa para avaliação da concordância intraobservador (Kappa $=0,71)$. A ficha clínica utilizada foi baseada nos estudos epidemiológicos realizados pela Organização Mundial de Saúde (OMS) ${ }^{10}$.

Os indivíduos foram examinados por um único cirurgião-dentista (CD) e os dados foram anotados na ficha clínica por auxiliares previamente treinados. $O$ exame foi realizado em uma sala com a criança sentada em cadeira e com luz natural e o auxílio de espelho bucal plano, sonda para exame epidemiológico bucal (sonda OMS), gaze e espátula de madeira ${ }^{11}$.

O exame dos dentes foi realizado utilizando índices preconizados pela OMS, o CPO-D médio (dentição permanente) e o ceo-d médio (dentição decídua), que demonstraram a soma dos dentes cariados, perdidos por cárie e obturados. O dente foi considerado presente na cavidade bucal quando qualquer parte da sua coroa estivesse visível; quando o dente permanente e o decíduo estavam presentes simultaneamente, foi anotado, apenas, 0 dente permanente ${ }^{12}$.

A elaboração do banco de dados e análise descritiva foi realizada com o software Statistical Package for Social Sciences (SPSS Inc., Chicago, IL, Estados Unidos da América), versão 14.0 for Windows. Para comparação de variáveis categóricas foi utilizado o teste do Qui-quadrado, já para as médias foi utilizado o teste t de Student para amostras independentes que apresentaram distribuição simétrica. A comparação das frequências alimentares e a média do CPO-D e ceo-d foi feita utilizando o teste ANOVA. Para todas as inferências foi utilizado um nível de significância de $5 \%$.

Esta pesquisa foi realizada de acordo com a resolução 466/12 do Conselho Nacional de Saúde e aprovada pelo Comitê de Ética em Pesquisa (CEP) da Escola Bahiana de Medicina e Saúde Pública (CAAE: 54637816.7.0000.5544).

\section{RESULTADOS}

Foram examinados 124 escolares, 61 indivíduos com AF e 63 saudáveis. Dados relacionados à idade, sexo, raça (autorreferida), grau de escolaridade da criança e da mãe, bem como rendimento familiar e procedência estão descritos na Tabela 1.

Tabela 1 - Características sociodemográficas da amostra.

\begin{tabular}{|c|c|c|c|}
\hline Variáveis & $\begin{array}{c}\text { Grupo AF } \\
(n=61)\end{array}$ & $\begin{array}{c}\text { Grupo } \\
\text { Comparação } \\
(n=63)\end{array}$ & Valor de $p$ \\
\hline Idade (anos) $\mathrm{m} \pm \mathrm{DP}$ & $12,4 \pm 2,9$ & $11,1 \pm 2,9$ & $0,014^{*}$ \\
\hline Faixa Etária & & & $0,119 * *$ \\
\hline 5 a 8 anos & $6(9,8)$ & $11(17,5)$ & \\
\hline 9 a 12 anos & $24(39,3)$ & $31(49,2)$ & \\
\hline 13 a 18 anos & $31(50,8)$ & $21(33,3)$ & \\
\hline Sexo & & & $0,605^{* *}$ \\
\hline Masculino & $34(55,7)$ & $38(60,3)$ & \\
\hline Raça & & & $0,191 * *$ \\
\hline Preta & $18(29,5)$ & $26(41,3)$ & \\
\hline
\end{tabular}




\begin{tabular}{|c|c|c|c|}
\hline Variáveis & $\begin{array}{c}\text { Grupo AF } \\
(n=61)\end{array}$ & $\begin{array}{c}\text { Grupo } \\
\text { Comparação } \\
(n=63)\end{array}$ & Valor de $p$ \\
\hline Parda & $42(69,9)$ & $32(50,8)$ & \\
\hline Outras & $1(1,6)$ & $5(8)$ & \\
\hline $\begin{array}{l}\text { Grau de Escolarida- } \\
\text { de }\end{array}$ & $(n=60)$ & $(n=61)$ & $0,114 * *$ \\
\hline Analfabeto & $4(6,7)$ & $3(4,9)$ & \\
\hline $1^{\circ} \mathrm{Grau}$ & $48(80,0)$ & $56(91,8)$ & \\
\hline $2 \mathrm{Grau}$ & $8(13,3)$ & $2(3,3)$ & \\
\hline $\begin{array}{l}\text { Escolaridade Ma- } \\
\text { terna }\end{array}$ & $(n=56)$ & $(n=56)$ & $0,902 * *$ \\
\hline Analfabeto & $2(3,6)$ & $1(1,8)$ & \\
\hline $1^{\mathrm{a}} \mathrm{Grau}$ & $28(50,0)$ & $31(55,4)$ & \\
\hline $2^{\mathrm{a}} \mathrm{Grau}$ & $23(41,1)$ & $21(37,5)$ & \\
\hline $3^{\circ} \mathrm{Grau}$ & $3(5,4)$ & $3(5,4)$ & \\
\hline Renda & $(n=57)$ & $(n=55)$ & $0,081 * *$ \\
\hline Sem renda & $8(14,0)$ & $3(5,5)$ & \\
\hline Até 1 SM & $40(70,2)$ & $35(63,6)$ & \\
\hline Maior que 2 SM & $9(15,8)$ & $17(30,9)$ & \\
\hline Procedência & & & $0,000 * *$ \\
\hline Capital & $17(27,9)$ & $57(90,5)$ & \\
\hline Interior & $44(72,1)$ & $6(9,5)$ & \\
\hline
\end{tabular}

* Teste T independente; ** Teste Qui-Quadrado; $m=$ média; $D P=D e s v i o$ Padrão; $S M=$ salário mínimo.

Fonte: Autoria própria

Não foram encontradas diferenças significativas entre os grupos quanto à frequência de escovação, porém em relação à visita ao dentista observou-se que os indivíduos com AF a faziam com maior frequência do que aqueles sem a hemoglobinopatia (grupo $\mathrm{AF}=85,2 \%$; grupo comparação $=69,8 \% ; p=0,040$ ).

Ao avaliar os índices de CPO-D e ceo-d, houve maior CPO-D e ceo-d para o grupo AF que para o grupo comparação, e este resultado foi estatisticamente significante com maior predominância do componente cariado na dentição permanente e decídua no grupo com AF (Tabelas 2 e 3).

Tabela 2-Média do CPO-D de crianças e adolescentes avaliados.

\begin{tabular}{lccc}
\hline \multicolumn{1}{c}{ Variáveis } & $\begin{array}{c}\text { Grupo AF } \\
(\mathbf{n}=61)\end{array}$ & $\begin{array}{c}\text { Grupo Compa- } \\
\text { ração } \\
(\mathbf{n}=63)\end{array}$ & Valor de $\mathbf{p}$ \\
\hline Condição dentária & $\mathrm{m} \pm \mathrm{DP}$ & $\mathrm{m} \pm \mathrm{DP}$ & \\
Cariado & $1,5 \pm 2,38$ & $0,8 \pm 1,23$ & $0,003^{*}$ \\
Perdido & $0,8 \pm 0,33$ & $0,98 \pm 0,3$ & $0,620^{*}$ \\
Obturado & $0,5 \pm 1,0$ & $0,24 \pm 0,7$ & $0,004^{*}$ \\
CPO-D & $2,1 \pm 2,7$ & $1,1 \pm 1,7$ & $0,013^{*}$ \\
\hline
\end{tabular}

*Teste $T$ independente; $m=$ média; $D P=D e s v i o$ Padrão. CPO-D - Média dos componentes $C$ (cariados), $P$ (perdidos ou extraídos por cárie) e $O$ (obturados ou restaurados) na dentição permanente. $p<0,05$.

Fonte: Autoria própria
Tabela 3 - Média do ceo-d em crianças avaliadas.

\begin{tabular}{lccc}
\hline \multicolumn{1}{c}{ Variáveis } & $\begin{array}{c}\text { Grupo AF } \\
(\mathbf{n = 2 3 )}\end{array}$ & $\begin{array}{c}\text { Grupo } \\
\text { Comparação } \\
(\mathbf{n}=\mathbf{2 4 )}\end{array}$ & Valor de $\mathbf{p}$ \\
\hline Condição dentária & $\mathrm{m} \pm \mathrm{DP}$ & $\mathrm{m} \pm \mathrm{DP}$ & \\
Cariado & $1,3 \pm 1,8$ & $0,7 \pm 1,12$ & $0,039^{*}$ \\
Extração Indicada & $0,65 \pm 1,23$ & $0,12 \pm 0,34$ & $0,000^{*}$ \\
Obturado & $0,35 \pm 0,8$ & $0,2 \pm 0,6$ & $0,222^{*}$ \\
ceo-d & $2,3 \pm 2,6$ & $0,88 \pm 1,2$ & $0,018^{*}$ \\
\hline
\end{tabular}

*Teste $T$ independente; $m=$ média; $D P=D e s v i o$ Padrão. ceo- $d$ - Média dos componentes c (cariados), e (extração indicada) e o (obturados ou restaurados) na dentição decídua. $p<0,05$.

Fonte: Autoria própria

Ao avaliar a associação entre o CPO-D e fatores socioeconômicos, indivíduos que tinham menor escolaridade e as famílias que tinham uma menor renda apresentavam um maior CPO-D, resultado estatisticamente significante - Tabela 4 e 5, respectivamente.

Tabela 4 - Comparação da média do CPO-D e ceo-d das crianças e dos adolescentes com AF em relação ao seu grau de escolaridade.

\begin{tabular}{lrcrr}
\hline & Analfabeto & 1 Grau & 2 Grau & $\begin{array}{r}\text { Valor } \\
\text { de } \mathbf{p}\end{array}$ \\
\hline Decíduos & $\mathrm{m} \pm \mathrm{DP}$ & $\mathrm{m} \pm \mathrm{DP}$ & $\mathrm{m} \pm \mathrm{DP}$ & \\
Cariado & 0,00 & $0,73 \pm 1,19$ & 0,00 & 0,59 \\
Perdido & 0,00 & $0,15 \pm 0,37$ & 0,00 & 0,72 \\
Obturado & $0,33 \pm 0,57$ & $0,21 \pm 0,63$ & 0,00 & 0,98 \\
ceo-d & $0,33 \pm 0,57$ & $0,95 \pm 1,26$ & 0,00 & 0,57 \\
\hline Permanentes & & & & \\
\hline Cariado & $5,00 \pm 5,59$ & $1,16 \pm 1,80$ & $1,87 \pm 2,35$ & $0,06^{*}$ \\
Perdido & 0,00 & $0,41 \pm 0,20$ & $0,37 \pm 0,74$ & 0,26 \\
Obturado & $0,25 \pm 0,50$ & $0,39 \pm 0,89$ & $1,50 \pm 1,85$ & $0,02^{*}$ \\
CPO-D & $5,25 \pm 5,5$ & $1,56 \pm 2,07$ & $1,13 \pm 1,08$ & $0,05^{*}$ \\
\hline
\end{tabular}

*Teste ANOVA. $p<0,05$.

Fonte: Autoria própria

Tabela 5 - Comparação da média do CPO-D e ceo-d das crianças e dos adolescentes com AF em relação a renda familiar.

\begin{tabular}{lrcrr}
\hline & Sem renda & $\mathbf{1 ~ S M}$ & $\begin{array}{c}\text { Mais 2 } \\
\text { SM }\end{array}$ & $\begin{array}{c}\text { Valor } \\
\text { de } \mathbf{p}\end{array}$ \\
\hline Decíduos & $\mathrm{m} \pm \mathrm{DP}$ & $\mathrm{m} \pm \mathrm{DP}$ & $\mathrm{m} \pm \mathrm{DP}$ & \\
cariado & $0,75 \pm 0,95$ & $1,50 \pm 2,00$ & 0 & 0,47 \\
perdido & $1,75 \pm 2,36$ & $0,44 \pm 0,78$ & 0 & 0,56 \\
obturado & 0,00 & $0,44 \pm 0,85$ & 0 & 0,32 \\
ceo-d & $2,50 \pm 3,10$ & $2,39 \pm 2,55$ & 0 & 0,9 \\
\hline Permanentes & & & & \\
\hline Cariado & $1,37 \pm 2,32$ & $1,21 \pm 1,78$ & $6,50 \pm 9,18$ & $0,07^{*}$ \\
Perdido & $0,25 \pm 0,70$ & $0,63 \pm 0,24$ & 0,00 & 0,35 \\
Obturado & $0,37 \pm 1,06$ & $0,46 \pm 0,97$ & 0,00 & 0,78 \\
CPO-D & $2,00 \pm 2,56$ & $1,70 \pm 2,15$ & $6,50 \pm 2,19$ & $0,03^{*}$ \\
\hline
\end{tabular}

*Teste ANOVA. $p<0,05 ; S M=$ salário mínimo.

Fonte: Autoria própria

Rev. Ciênc. Méd. Biol., Salvador, v. 19, n. 2, p. 276-281, mai./ago. 2020 
A frequência de consumo de carboidratos nos 103 indivíduos avaliados foi maior no grupo comparação quando foi observada a dieta semanal e diária, sendo este resultado estatisticamente significativo. No grupo comparação, 58,6\% dos indivíduos apresentaram um consumo de carboidratos maior ou igual a 4x por semana, já no grupo AF foram $35,6 \%(p=0,018)$. Quanto ao consumo diário de carboidratos, $65,5 \%$ dos indivíduos do grupo comparação tiveram uma ingesta maior ou igual a $4 x \mathrm{e}$ $44,4 \%$ do grupo AF $(p=0,022)$. Ao comparar a frequência da ingestão de açúcar com os índices de cárie em ambas as dentições, para os grupos separadamente, as crianças e os adolescentes com AF que consumiam uma dieta mais cariogênica apresentaram CPO-D e ceo-d mais que o dobro de vezes maior que as do grupo comparação, apesar desta diferença não ser significativa entre os grupos.

\section{DISCUSSÃO}

A AF, doença de caráter recessivo e hereditário, mais comumente observada em indivíduos negros, vem mudando seu perfil ao longo do tempo, devido à migração dos povos e miscigenação racial ${ }^{13}$. Neste estudo foi encontrada uma maior prevalência de crianças e adolescentes autodenominados de raça parda com AF, apesar da Bahia ser o estado com a maior presença de negros no Brasil ${ }^{1}$.

Em relação aos aspectos socioeconômicos, nesta pesquisa, a amostra foi semelhante para os grupos em relação a quase todos os aspectos, exceto em relação à procedência e à idade. A maioria dos indivíduos cursava o primeiro grau, realidade aplicada a sua genitora, e tinham renda familiar de até um salário mínimo. Para a procedência, os indivíduos com $\mathrm{AF}$, na maioria, eram do interior, o que pode interferir diretamente nos resultados encontrados, já que nestes locais, muitas vezes não há tratamento adequado para as enfermidades bucais. Em relação à média de idade, as crianças com $\mathrm{AF}$ eram um pouco mais velhas, devido à menor quantidade de crianças examinadas na faixa etária de 5 a 8 anos.

Outros estudos corroboram com este no que tange às crianças com $A F$, em relação a renda ${ }^{14-16}$, raça ${ }^{15,16} \mathrm{e}$ procedência ${ }^{17}$.

Fatores socioeconômicos têm mostrado influência no desenvolvimento da cárie ${ }^{14,18}$. Indivíduos de baixa renda normalmente tendem a apresentar níveis de educação deficientes e seu acesso às informações sobre cuidados de saúde, como o próprio atendimento, são menores. A renda também pode ser um fator indireto para determinar a suscetibilidade à cárie dentária. Laurence et al. relataram em seu estudo que africanos com nível socioeconômico baixo, com AF, tinham um risco maior de cárie e esses resultados forneciam evidências de que indivíduos de baixa renda são mais propensos a ter mais dentes cariados em comparação com indivíduos sem a doença ${ }^{19}$. Estes resultados concordam com o presente estudo, em que a média do CPO-D foi igual a 2 em crianças cujos rendimentos familiares eram inferiores ao salário mínimo. A educação é o indicador mais amplamente usado para medir o perfil socioeconômico em epidemiologia. Neste estudo, pôde-se observar seu impacto, pois crianças e adolescentes com menor nível educacional cujas mães apresentavam menor grau de escolaridade revelaram maior índice de cárie, semelhante ao verificado em outros estudos ${ }^{20-22}$.

A cárie dentária é uma doença multifatorial e o controle dos seus fatores de risco pode ser desafiador. Fatores socioeconômicos foram previamente associados como preditores de risco a cárie. Indivíduos de baixa renda tendem a ter menos conhecimento sobre cuidados com higiene bucal, bem como menor acesso às ações de promoção de saúde promovidas ${ }^{23,24}$. Os resultados deste estudo encontraram a baixa renda familiar como um fator significativo para prevalência de cárie em crianças maiores.

Ao avaliar a doença individualmente, no presente estudo, os índices CPO-D e ceo-d encontrados foram de 2,1 e 2,3 para indivíduos com AF e 1,1 e 0,88 para grupo comparação, respectivamente. Principalmente com relação ao ceo-d de 2,3 encontrado naqueles com $A F$, este achado aproxima-se do estudo de Luna et al., que estudaram apenas crianças com AF, encontrando um CPO-D de 1,5 e ceo-d de 2,12 ${ }^{14}$. Para Fernandes et al., que avaliaram 56 crianças e 50 adolescentes de 8 a 14 anos de idade com AF e 205 e 180, respectivamente, do grupo controle em um Hemocentro em Minas Gerais, Brasil, o CPO-D foi menor $(1,3)$ no grupo anemia e maior $(1,8)$ no controle. Além disso, os indivíduos com AF, no geral, apresentavam melhor condição de saúde bucal ${ }^{15}$. Neste estudo, a despeito de os indivíduos com AF terem pior saúde bucal, o resultado observado está de acordo com dados do SB Brasil 2010, que encontrou ceo- $d=2,43$ e CPO-D $=2,07^{25}$.

De acordo com Ralstrom et al., ao examinar 54 adolescentes americanos afrodescendentes com idade média de 14 anos, com genótipos de células falciformes HbSS e HbSC, o CPO-D médio encontrado foi de 1,94 no grupo doença e 2,96 no grupo controle. Esta pequena diferença entre os índices pode ser justificada pelo acesso às ações de promoção de saúde a que pais e portadores de DF têm desde cedo e à frequente exposição ao fluoreto, uma vez que são estimulados ao constante consumo de água fluoretada a fim de evitar a desidratação, o que poderia potencialmente expô-los mais ao fluoreto que seus controles ${ }^{26}$.

Entretanto, para Singh et al., na Índia, com 750 pacientes de 3 a 15 anos de idade com AF e Betalassemia, foi verificado um CPO-D de 6,59 para os pacientes com falcemia. Este valor difere bastante dos valores encontrados neste estudo e nos demais, provavelmente por diferentes políticas dos sistemas de saúde da região, tornando o tratamento menos acessível ${ }^{27}$.

A presença da cárie, a falta de atendimento diante da necessidade, bem como seu agravamento, leva à necessidade de tratamentos mais complexos e a perdas dentárias, tanto na população geral como na população 
estudada, na qual as características sociodemográficas se assemelham, número refletido no SB Brasil 201025-27.

Em relação aos cuidados sobre a saúde bucal, os adolescentes são mais vulneráveis a estes fatores, uma vez que já não são mais beneficiados pelos cuidados e atenção dos pais em relação a quando eram crianças e, muitas vezes, não apresentam a maturidade da vida adulta $^{28}$. Além disso, neste período existe um maior risco para o desenvolvimento de doenças bucais como cárie, o que pode ser observado neste estudo, já que sua prevalência teve um incremento com a idade.

A fim de verificar a associação entre DF e cárie em afro-americanos, Laurence et al. aplicaram um questionário para obter informações sobre exposição a fatores de risco para a cárie, incluindo nível socioeconômico, acesso aos cuidados dentários, frequência de escovação dos dentes e de consumo de açúcar. Os indivíduos saudáveis escovavam os dentes duas vezes ao dia, além de ir ao dentista com mais regularidade em relação aos pacientes doentes ${ }^{19}$. Mahmoud et al. questionaram a frequência dos hábitos de higiene oral na sua pesquisa e não comprovaram associação entre os hábitos e $\mathrm{AF}$, apesar de $90 \%$ dos pacientes escovarem os dentes apenas uma vez ao dia ${ }^{29}$.

Al-Alawi et al. analisaram a saúde bucal e severidade da AF em 66 indivíduos com AF e saudáveis em relação aos fatores de risco de cárie, como nível de renda, uso de fio dental e escovação. A maioria dos pacientes com AF estava ciente dos efeitos da cárie em sua saúde bucal, escovavam os dentes diariamente e visitaram o dentista apenas quando sentiam dor ${ }^{30}$. Neste estudo, a maioria dos indivíduos dos grupos escovavam os dentes duas vezes por dia, apesar de vários estudos aconselharem a escovação pelo menos três vezes ao dia, após as principais refeições ${ }^{28,31}$. Sobre as consultas odontológicas, os pacientes com AF frequentavam mais o dentista, apesar de não ser verificada uma melhora na sua condição de saúde bucal em relação aos pacientes saudáveis, provavelmente devido à presença de fatores associados à doença como uso de medicação contínua e número de hospitalizações, que podem interferir diretamente na saúde destes indivíduos.

Em relação à dieta dos indivíduos avaliados, foram selecionados alimentos considerados potencialmente cariogênicos e que haviam sido usados em outros estudos: achocolatados, refrescos de caixa, sucos, refrigerantes,

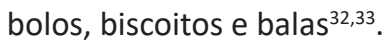

No que tange ao indivíduo, aqueles com AF apresentaram uma dieta menos cariogênica em relação ao grupo comparação, apesar de apresentarem uma ingestão diária acima de quatro vezes de sacarose em $44,4 \%$ da amostra. Ao analisar os índices de cárie em ambas as dentições e sua frequência de consumo, foi observado que mesmo com a dieta com menos açúcar, estes indivíduos apresentavam o CPO-D e o ceo-d duas ou mais vezes maior que aqueles sem a doença, podendo levar ao questionamento se outros fatores inerentes à própria $A F$ favoreçam o desenvolvimento das lesões de cárie. Esses valores foram próximos aos encontrados por Peres et al. no seu estudo, em que os pacientes, apesar de saudáveis, consumiam duas a três vezes ao dia produtos cariogênicos e tinham quatro vezes mais a doença do que os que consumiam uma vez e aos de Medeiros, em que os indivíduos com AF consumiam $88 \%$ de dieta cariogênica, valor próximo aos deste estudo, $80 \%$ para uma dieta cariogênica semanal e $68,8 \%$ para diária ${ }^{34,35}$.

Foi observado, tanto no Brasil como em outros países, que nos casos mais graves da doença, em que o paciente apresenta um comprometimento sistêmico afetando vários sistemas e órgãos, necessitando de internações para transfusões e tratamentos, os cuidados básicos com a saúde bucal, como a escovação diária após as principais refeições, o tipo de dieta consumida, a visita ao dentista regularmente foram negligenciados, o que pode levar a uma maior predisposição para desenvolver doenças bucais ${ }^{14,17,19,26,27}$.

Vale ressaltar que ambos os grupos avaliados são tratados, em sua maioria, no Sistema Único de Saúde, assistência de saúde pública que oferece uma atenção básica de tratamento a estes pacientes, sem adotar um programa efetivo de promoção de saúde contínuo. Aos pacientes com AF é oferecido no próprio centro de atendimento para cuidados com a sua saúde geral, mas o atendimento odontológico não consegue absorver toda a demanda das necessidades de atendimento para os problemas bucais, principalmente pela falta de atendimento especializado nas diferentes áreas da Odontologia.

Ademais, salienta-se a ocorrência do racismo institucional que contribui para a vulnerabilidade desse grupo populacional, ampliando barreiras ao acesso, ainda que seja decorrente de atitudes e comportamentos por preconceito involuntário, ignorância ou negligência ${ }^{36}$. Dessa forma, medidas de atenção à saúde bucal desde as idades mais precoces devem ser adotadas, tendo como princípio básico a educação em saúde, a socialização e a racionalização dos recursos públicos.

\section{CONCLUSÃO}

As crianças e os adolescentes com AF eram, em sua maioria, da raça parda, apresentavam nível socioeconômico baixo e tinham maior procedência do interior. Em relação à cárie, foi observado um maior índice em ambas as dentições, apesar de a dieta ter sido menos cariogênica na frequência de consumo diário e semanal em relação aos indivíduos saudáveis. É possível que a prevalência maior de cárie para crianças e adolescentes com AF esteja associada a outros fatores inerentes à doença.

\section{REFERÊNCIAS}

1. BRASIL. Ministério da Saúde. Doença falciforme: condutas básicas para tratamento. Brasília: Secretaria de Atenção à Saúde, Departamento de Atenção Especializada, 2012.

2. BRASIL. Ministério da Saúde. Doença falciforme: saúde bucal: prevenção e cuidado. Brasília: Secretaria de Atenção à Saúde, Departamento de Atenção Hospitalar e de Urgência. 2014. 
3. ADORNO, E.V. et al. Hemoglobinopathies in newborns from Salvador, Bahia, Northeast Brazil. Cad. Saúde Pública, Rio de Janeiro, v. 21, n.1, p. 292-298, Jan/Feb. 2005

4. CANÇADO R. D.; JESUS J.A. A doença falciforme no Brasil. Rev. Bras. Hematol. Hemoter, São Paulo, v. 29, n. 3, p. 203-206, 2007.

5. HOSNI, J. S. et al. Protocolo de atendimento odontológico para paciente com anemia falciforme. Arq. Bras. Odontol., [s.l], v. 4, n. 2, p. 104-112, 2008.

6. PARADOWSKI, K. Pathophysiology and perioperative management of sickle cell disease. J Perioper Pract, v. 25, n. 6, p. 101-104, 2015.

7. ACHARYA, S. Oral and dental considerations in management of sickle cell anemia. Int. J. Clin. Pediatr. Dent., [s.I], v. 8, n. 2, p. 141-144, May/ Aug. 2015.

8. BOTELHO D.S. et al. Perfil sistêmico e conduta odontológica em pacientes com anemia falciforme. Int. J. Dent., Recife, v. 8, n.1, p.2835, jan./mar. 2009.

9. BRASIL. Ministério da Saúde. Manual de educação em saúde. Brasília: Secretaria de Atenção à Saúde, Departamento de Atenção Especializada, 2008.

10. ORGANIZAÇÃO MUNDIAL DE SAÚDE (OMS). Levantamentos básicos em saúde bucal. 4 ed. São Paulo: Santos; 1999.

11. BRASIL. Ministério da Saúde. Orientações para a coleta e análise de dados antropométricos de saúde: norma técnica do Sistema de Vigilância Alimentar e Nutricional - SISVAN. Brasília: Secretária de Atenção à Saúde, Departamento de Atenção Básica, 2011.

12. BRASIL. Ministério da Saúde. SB Brasil 2010: Manual da Equipe de Campo. Brasília: Secretaria de Vigilância à Saúde, Secretaria de Atenção à Saúde, Departamento de Atenção Básica, Coordenação Nacional de Saúde Bucal, 2009. p. 37-42.

13. CALVO-GONZALEZ E.; ROCHA V. "Está no sangue": a articulação de ideias sobre "raça", aparência e ancestralidade entre famílias de portadores de doença falciforme em Salvador, Bahia. Revista de Antropologia, São Paulo, v. 53, n. 1, p. 278-320, 2010.

14. LUNA, A.C. et al. A. Caries prevalence and socioeconomic factors in children with sickle cell anemia. Braz Oral Res, São Paulo, v. 26, p. 43-49; 2012.

15. FERNANDES M. L. M. F. et al. Caries prevalence and impact on oral health-related quality of life in children with sickle cell disease: crosssectional study. BMC Oral Health, London, v. 38, n. 2, p. 106-112, 2016.

16 SOARES, F. F. et al. Condições de saúde bucal e fatores sociodemográficos de crianças de 6 a 96 meses com doença falciforme no Estado da Bahia. Rev. Odontol. UNESP, Araraquara, v. 39, n. 2, p. 115-121, mar./abr. 2010

17. REZENDE, P. V. et al Acute splenic sequestration in a cohort of children with sickle cell anemia. J. Pediatr. (Rio J), Rio de Janeiro, v. 85, n. 2, p. 163-169, Mar./Apr. 2009.

18. ÇOLAK, H. et al. Early childhood caries update: A review of causes, diagnoses and treatments. J Nat Sci Biol Med, v. 4, n. 1, p. 29-38, 2013.

19. LAURENCE, B. The association between sickle cell disease and dental caries in African Americans. Spec. Care Dentist,, Chicago, v. 26, p. 95-100, 2006.
20. BORGES, T. S. et al. Oral hygiene, dietary habits and prevalence of dental caries in adolescents from rural and urban areas in Rio Grande do Sul, Brazil. RGO (Porto Alegre), Porto Alegre, v. 65, n. 2, p. 139-147, 2017.

21. FERREIRA S. H. et al. Dental caries in 0- to 5-year-old Brazilian children: prevalence, severity, and associated factors. Int. J. Paediatr. Dent., Oxford, v. 17, n. 4, p. 289-296, p. 289-296, July 2007.

22. KRAMER, P. F. et al. Gains in children's dental health differ by socioeconomic position: evidence of widening inequalities in southern Brazil. Int. J. Paediatr. Dent., Oxford, v. 25, n. 6, p. 383-392, nov 2015.

23. AKPABIO A.; KLAUSNER C. P.; INGLEHART M. R. Mothers'/guardians' knowledge about promoting children's oral health. J. Dent. Hyg., Chicago, v. 82, n. 1, p. 12.

24. GISLON L. C.; BOTTAN E. R.; STAIMBACH C. O.; RAFAELI C. Conhecimento de mães sobre saúde bucal na infância. J. Oral Invest., Passo Fundo, v. 6, n. 2, p. 10-20, 2017.

25. BRASIL. Ministério da Saúde. Projeto SB Brasil 2010: Pesquisa Nacional de Saúde Bucal: resultados principais. Brasília: Coordenação Nacional de Saúde Bucal, 2011.

26. RALSTROM, E. et al. The impact of sickle cell disease on oral healthrelated quality of life. Pediatr. Dent., Chicago, v. 36, p. 24-28, 2014.

27. SINGH, J. et al. Dental and periodontal health status of Beta thalassemia major and sickle cell anemic patients: a comparative study. J. Int. Oral Health, v. 5, n. 5, p. 53-58, Sept./Oct. 2013.

28. DAVOGLIO, R. S. et al. Fatores associados a hábitos de saúde bucal e utilização de serviços odontológicos entre adolescentes. Cad. Saúde Pública, Rio de Janeiro, v. 25, n. 3, p. 655-667, mar 2009.

29. MAHMOUD M. O.; GHANDOUR I. A.; ATALLA B. Association between sickle cell anemia and periodontal disease among 12 to 16 years old Sudanese children periodontal disease. Oral Health Prev. Dent., New Malden, v. 11, n. 4, p. 375-381, 2013.

30. AL-ALAWI, H. et al. The association between dental and periodontal diseases and sickle cell disease. A pilot case-control study. Saudi Dent. J., [s.I], v. 27, p. 40-43, 2015.

31. GUEDES-PINTO A. C. Odontopediatria. 8 ed. São Paulo: Editora Santos, 2010.

32. ZERO D. T. Sugars - The arch criminal? Caries Res., Basel, v. 38, p. 277-285, 2004.

33. ALMASI, A. et al. Effect of Nutritional Habits on Dental Caries in Permanent Dentition among Schoolchildren Aged 10-12 Years: A ZeroInflated Generalized Poisson Regression Model Approach. Iran J. Public Health, Teharan, v. 45, n. 3, p. 353-361, mar 2016.

34. PERES K. G. A.; BASTOS J. R. M.; LATORRE M. R. D. O. Severidade de cárie em crianças e relação com aspectos sociais e comportamentais. Rev. Saúde Pública, São Paulo, v. 34, n. 4, p. 402-408, 2000.

35. MEDEIROS, M. L. B. B. Análise de fatores de risco de cárie dentária em pacientes portadores de doença falciforme. 2012 Dissertação (Mestrado em Pesquisa em Saúde) - Centro Universitário CESMAC, Alagoas, 2012.

36. KALCKMANN, S. et al. Racismo institucional: um desafio para a eqüidade no SUS? Saúde Soc., São Paulo, v. 16, n. 2, p. 146-155, 2007. 